\title{
Pregnancy and the biliary tract
}

\author{
Tuvia Gilat MD, Fred Konikoff MD
}

\begin{abstract}
T Gilat, F Konikoff. Pregnancy and the biliary tract. Can J Gastroenterol 2000;14(Suppl D):55D-59D. Pregnancy induces many physiological changes, some of which may have pathological results. In population studies, gallstones were found in $6.5 \%$ to $8.4 \%$ of nulliparous women, and in $18.4 \%$ to $19.3 \%$ of women with two to three or more pregnancies. In women followed throughout pregnancy, neoformation of gallstones was documented in $3 \%$ to $8.1 \%$ depending on the population. Some $20 \%$ to $30 \%$ of these gallstones redissolve postpartum. The frequency of biliary colic during pregnancy is controversial, and the recommended therapeutic approach during pregnancy is conservative. When essential, invasive procedures are relatively well tolerated, preferably during the second trimester. Biliary sludge disappears postpartum in the great majority. Gallstones and sludge are most likely caused by biliary stasis, prolonged intestinal transit and increased cholesterol saturation of bile, which were all demonstrated to occur during pregnancy.
\end{abstract}

Key Words: Biliary sludge; Biliary tree; Gallstones; Pregnancy

\section{Grossesse et voies biliaires}

RÉSUMÉ : La grossesse donne lieu à de nombreux changements physiologiques, dont certains peuvent avoir des conséquences pathologiques. Des études démographiques ont révélé la présence de calculs biliaires chez 6,5 à $8,4 \%$ des femmes nullipares et chez 18,4 à 19,3 \% des femmes ayant eu au moins deux grossesses. Chez des femmes qui ont été suivies pendant toute la grossesse, la néoformation de calculs biliaires a été objectivée chez 3 à $8,1 \%$ des patientes selon la population étudiée. Quelque 20 à $30 \%$ de ces calculs biliaires se dissolvent après l'accouchement. La fréquence de la colique hépatique pendant la grossesse est controversée, et on recommande une démarche thérapeutique traditionnelle pendant la grossesse. Lorsqu'elles sont essentielles, les interventions effractives sont bien tolérées, de préférence au cours du deuxième trimestre. La boue biliare disparait après l'accouchement chez la vaste majorité des femmes. Le plus souvent, les calculs biliaires et la boue biliaire sont imputables aux phénomènes que l'on observe pendant la grossesse, notamment la stase biliaire, la prolongation du transit intestinal et la saturation de la bile en cholestérol.
Presting egnancy induces physiological changes and pathological complications in the biliary tract. In this article, we review the major complications - gallstones and biliary sludge - as well as the physiological effects of pregnancy that form the basis for these complications.

\section{GALLSTONES}

In the past, there has been controversy as to whether pregnancy, particularly multiple pregnancies, contributes to the formation of gallstones. This controversy was caused by inappropriate comparisons that disregarded confounding factors. In particular, the paucity of gallstones in populations with high birth rates in developing countries has been cited as evidence that multiple births are not a factor in the formation of gallstones. Such comparisons are flawed; comparisons should be made within a defined population having similar genetic and environmental backgrounds, with the number of pregnancies being the major variable. Today it is clear that both environmental and genetic factors are important in the genesis of gallstones and that these factors should be kept relatively constant in comparisons. Large scale epidemiological studies were recently performed within relatively stable populations that yielded quite uniform results.

\section{POPULATION STUDIES}

The results of several defined population studies are shown in Table 1. The Rome Group for the Epidemiology and Prevention of Cholelithiasis (GREPCO) study (1) investigated employees of government ministries in Rome; the Sirmione study (2) evaluated inhabitants of a village in Northern Italy; and a study in Denmark (3) was performed using a random sample of women in Copenhagen county.

This mini-review was prepared from a presentation made at the World Congress of Gastroenterology, Vienna, Austria, September 6 to 11, 1998 Department of Gastroenterology, Tel-Aviv Sourasky Medical Center and Minerva Center for Cholesterol Gallstones and Lipid Metabolism in the Liver, Tel-Aviv University, Israel

Correspondence and reprints: Dr Tuvia Gilat, Department of Gastroenterology, Tel-Aviv Medical Center, 6 Weizman Street, Tel-Aviv, Israel 64239.

Telephone+972-3-5231197, fax+972-3-6974622, tuvgilat@netvision.net.il

Received for publication February 2, 1999. Accepted February 5, 1999 
TABLE 1

Gallstone prevalence and parity - Population studies

\begin{tabular}{lccc}
\hline Study & $\mathbf{n}$ & Nulliparous (\%) & $\begin{array}{c}\text { Two to three } \\
\text { pregnancies (\%) }\end{array}$ \\
\hline GREPCO Study (1) & 1081 & 8.4 & 18.4 \\
Barbara et al (2) & 1033 & 6.5 & 19.2 \\
Jorgensen (3) & 1765 & 6.9 & 19.3 \\
\hline
\end{tabular}

GREPCO Rome Group for the Epidemiology and Prevention of Cholelithiasis

TABLE 2

Gallstone formation during pregnancy

\begin{tabular}{lcccc}
\hline & \multicolumn{4}{c}{ Percentage with gallstones } \\
Study & $\mathbf{n}$ & Nulliparous & 1st trimester & Postpartum \\
\hline $\begin{array}{c}\text { Valdivieso } \\
\text { et al (7) }\end{array}$ & 1130 & 1.3 & & 12.2 \\
$\begin{array}{c}\text { Glasinovic } \\
\text { et al (8) }\end{array}$ & 259 & 3.1 & 11.2 \\
$\begin{array}{c}\text { Maringhini } \\
\text { et al (9) }\end{array}$ & 272 & 6 & 9.6 \\
$\begin{array}{c}\text { Tsimoyiannis } \\
\text { et al (10) }\end{array}$ & 669 & $1.6^{*}$ & $4.6^{*}$ \\
\hline
\end{tabular}

*Percentage represents multiparous women only

All three studies showed a two to three times higher crude prevalence of gallstones in women who had two to three or more pregnancies, compared with nulliparous women. The GREPCO group (4) also correlated the effects of number of pregnancies and age with gallstone frequency. They showed that gallstones were more frequent in women after one pregnancy than in nulliparous women. The frequency increased after two pregnancies and again after three or more pregnancies. This effect was much more marked in younger women (ages 25 to 30 years versus 35 to 40 years). Several population studies attempted to quantify the risk of gallstones caused by multiple pregnancies, adjusting for at least some known confounding factors. The number of multiple pregnancies and the adjustment for confounding factors were not uniform in the various studies. Nevertheless, results of studies performed in Sirmione (2), Framingham (5) and a very large multicentre study in Italy (Multicenter Italian Study on Epidemiology of Cholelithiasis [MICOL]) (6) were surprisingly similar. The relative risks were 1.7, 1.6 and 1.7, respectively. These and other studies provided definitive evidence that multiple pregnancies are a risk factor for the development of gallstones.

\section{DIRECT STUDIES}

Several groups performed abdominal ultrasound examinations of women in the immediate postpartum period and compared the results with those of examinations performed in the same women at the beginning of pregnancy or in agematched nulliparous women (Table 2). Chile is a high prevalence area for gallstones. In two large Chilean studies, $12.2 \%$ (7) and $11.2 \%$ (8) of women were found to have gall-
TABLE 3

Clinical course of gallstones during pregnancy Direct studies

\begin{tabular}{lccc}
\hline Study & n & Biliary colic (\%) & Remarks \\
\hline Maringhini et al (13) & 298 & $\begin{array}{c}\text { "No correlation between } \\
\text { pain and stones" }\end{array}$ & $\begin{array}{c}\text { Postpartum } \\
\text { questionnaire }\end{array}$ \\
Maringhini et al (9) & 272 & 29 & $\begin{array}{c}\text { Prospective } \\
\text { study }\end{array}$ \\
Valdivieso et al (7) & 980 & 31 & $\begin{array}{c}\text { Postpartum } \\
\text { questionnaire }\end{array}$ \\
\hline
\end{tabular}

stones in the postpartum period compared with $3.1 \%$ in the same women at the beginning of pregnancy and $1.3 \%$ in nulliparous women.

The prevalence of gallstones is lower in Sicily (9) and particularly in Greece (10), and these differences are reflected in Table 2. While the methodologies in these and the other studies cited in this review were not uniform, the findings were similar. The data from all three areas, Chile, Sicily and Greece, clearly document the de novo development of gallstones during the course of pregnancy.

\section{NATURAL HISTORY OF GALLSTONES DURING PREGNANCY}

The predominant view is that symptomatic cholelithiasis is rare in pregnancy. Several large studies cite a prevalence of symptoms or complications in the order of $0.05 \%$ to $0.3 \%$ or $0.1 \%$ during pregnancy $(11,12)$. These studies were, however, largely based on retrospective reviews of charts, which are inaccurate in relation to symptoms and more reliable in relation to complications. There are, however, more direct studies in which women were questioned in the postpartum period $(7,13)$, or, even better, in which they were followed and questioned at regular intervals throughout pregnancy (9). The results conflict and are somewhat confusing (Table 3 ).

Maringhini et al (13) questioned women in the postpartum period and concluded that there was "no correlation between pain (biliary colic) and stones". Six years later, they followed another group of women at regular intervals throughout pregnancy and concluded that 29\% had biliary colic (9). A study from Santiago (7) questioned women in the postpartum period and determined that $31 \%$ had biliary colic during pregnancy. A study in Palermo (9) concluded that only 'old' stones, preceding pregnancy, caused symptoms of colic; while a study in Santiago (7) concluded that mainly stones larger than $10 \mathrm{~mm}$ in diameter, even if formed during pregnancy, caused colic. Clearly, more direct studies are needed to reach valid conclusions.

\section{TREATMENT OF SYMPTOMATIC CHOLELITHIASIS DURING PREGNANCY}

There is a consensus in relation to the therapeutic approach to symptomatic cholelithiasis during pregnancy (14-16). Treatment should be primarily conservative at all stages of pregnancy. If symptoms or complications mandate invasive 
TABLE 4

Outcome of gallstones after pregnancy

\begin{tabular}{lccc}
\hline & & \multicolumn{2}{c}{ Percentage with gallstones } \\
Study & $\mathbf{n}$ & Postpartum & Follow-up* \\
\hline Valdivieso et al (7) & 980 & 12.2 & -29 \\
Maringhini et al (13) & 298 & 5.3 & -14 \\
Maringhini et al (9) & 272 & 9.6 & -30 \\
\hline
\end{tabular}

*Percentage diminution

therapy, this should be preferably performed during the second trimester. If cholecystectomy is required, laparoscopic surgery is recommended. Numerous small series indicate the relative safety of laparoscopic cholecystectomy during pregnancy. Endoscopic retrograde cholangiopancreatography (with shielding of the abdomen), papillotomy and even surgery have been performed during pregnancy with relatively good results for mother and fetus $(14,17)$.

\section{OUTCOME OF GALLSTONES AFTER DELIVERY}

Some of the stones formed during pregnancy dissolve in the months following delivery. This has been well documented in several studies (Table 4). The dissolution rate may approach $25 \%$ to $30 \%$. When the conditions leading to gallstone formation disappear (stasis, lithogenic bile), dissolution occurs in some cases. This should be kept in mind when considering the treatment of gallstones formed during pregnancy.

\section{BILIARY SLUDGE}

Biliary sludge is a term used for low amplitude sonographic echoes seen in the gallbladder, which move with gravity but do not cast an acoustic shadow. Studies performed by Lee et al (18) have shown that biliary sludge is composed mostly of biliary mucus and cholesterol crystals. Bilirubin granules may also be present. Studies performed primarily by Maringhini and his groups $(9,13)$ (Table 5) have demonstrated that biliary sludge is very common in pregnancy. Some $30 \%$ of women have biliary sludge in their gallbladder close to delivery. Unlike gallstones, the sludge disappears in the majority of women in the months following delivery. Biliary sludge is closely associated with gallstones; in experimental animals, it has been shown to precede gallstones. In humans, it is associated with gallstones or conditions leading to gallstones, such as parenteral nutrition (19-22). Biliary sludge may be one of the pathways leading to gallstone formation. However, during pregnancy, only a fraction of women with sludge develop gallstones.

\section{PHYSIOLOGICAL CHANGES IN THE BILIARY SYSTEM DURING PREGNANCY}

Pregnancy induces physiological changes in many body systems. The changes in the biliary tree and bile are marked, and contribute to the formation of biliary sludge and gallstones. Only the major changes are discussed here.

Impaired gallbladder motility: Everson (23) performed a series of elegant studies of gallbladder motility. Twenty-two
TABLE 5

Presence of biliary sludge in pregnancy

\begin{tabular}{lcccc}
\hline Study & $\mathbf{n}$ & $\begin{array}{c}\text { First } \\
\text { Trimester }\end{array}$ & Postpartum & Follow-up \\
\hline $\begin{array}{c}\text { Maringhini } \\
\text { et al (13) }\end{array}$ & 298 & & $26 \%$ & $4 \%$ \\
$\begin{array}{c}\text { Maringhini } \\
\text { et al (9) }\end{array}$ & 272 & $15 \%$ & $38 \%$ & $16 \%$ \\
\hline
\end{tabular}

pregnant women were studied by ultrasonography hourly throughout the day and were compared with 22 nonpregnant women. The gallbladder volume was significantly greater in the pregnant women at all hours tested, before and after meals. When gallbladder motility was tested in the same two groups, the fasting volume was larger in the pregnant women (approximately $30 \mathrm{~mL}$ versus $18 \mathrm{~mL}$ ), but the emptying rates were similar in both groups. The main difference was a much larger residual volume in the pregnant women (approximately $12 \mathrm{~mL}$ versus $4.5 \mathrm{~mL}$ ). Tsimoyiannis et al (10) followed 649 women throughout pregnancy and measured the gallbladder volume using ultrasonography. The mean fasting gallbladder volume in early pregnancy was $12 \mathrm{~mL}$, and it rose to $26 \mathrm{~mL}$ in the ninth month of pregnancy. Seven days postpartum, the volume was $13 \mathrm{~mL}$. The mean residual volume in early pregnancy was $4 \mathrm{~mL}$, rising to $9 \mathrm{~mL}$ in the ninth month. One week postpartum, it was $4 \mathrm{~mL}$. Thus, both the fasting and residual volume more than doubled during pregnancy, returning to normal shortly after delivery. Impaired gallbladder emptying is well documented in cholelithiasis. It has been shown to precede stone formation in experimental lithogenesis (22) and to exist in patients with gallstones, persisting after stone dissolution (24). It was also a factor in stone recurrence following dissolution (25). Other conditions inducing gallbladder stasis, such as parenteral alimentation (26) or octreotide therapy (27), were proven to be lithogenic.

Impaired motility of the gastrointestinal tract: Pregnancy induces hypomotility throughout the gastrointestinal tract, probably via high progesterone levels. Lower esophageal sphincter pressure has been shown to decrease progressively to very low levels during pregnancy, returning to normal shortly after delivery (23). In the context of gallstones, small bowel transit time becomes progressively longer throughout pregnancy, eventually returning to normal after delivery (23). Impaired small bowel transit has been shown to be a factor in gallstone disease (22) and occurs during octoreotide therapy, which is known to induce gallstones $(27,28)$. Prolonged large bowel transit has also been shown to be a factor in gallstone disease $(29,30)$; however, studies of large bowel transit during pregnancy have produced conflicting results (23).

Lithogenic changes in the composition of bile: In human gallstone disease, bile is supersaturated with cholesterol. Impaired gallbladder emptying, a nucleation defect and other factors coexist. Cholesterol supersaturation of bile has also been shown to develop during pregnancy. Valdivieso et al 


\section{TABLE 6}

Effects of pregnancy on the gastrointestinal tract

Gallbladder stasis

Prolonged intestinal transit

Supersaturation of bile with cholesterol

Biliary sludge

All of the above are lithogenic factors

(7) studied duodenal bile composition in women, shortly after delivery and 40 days later, and compared it with bile composition of matched nulliparous women. Cholesterol concentration of duodenal bile in the nulliparous women was $5.6 \mathrm{mM}$ and the cholesterol saturation index (CSI) was 89. In the women after delivery, cholesterol concentration was $9 \mathrm{mM}$ and the CSI was 131, representing a rise of about $50 \%$. Forty days postpartum, the levels returned to normal. Cholesterol concentration was $6.1 \mathrm{mM}$ and the CSI was 89 . Kern et al (31) studied duodenal bile composition in 23 pregnant women in comparison with 23 nonpregnant women. They showed that the cholesterol to bile salt ratio was increased in the pregnant women, who secreted more cholesterol per mole of bile acids at various secretory rates. The same was true for the cholesterol to phospholipid ratio; it was also higher in the pregnant women. Bile clearly becomes more supersaturated with cholesterol during pregnancy.

\section{REFERENCES}

1. Prevalence of gallstone disease in an Italian adult female population. Rome Group for the Epidemiology and Prevention of Cholelithiasis (GREPCO). Am J Epidemiol 1984;119:796-805.

2. Barbara L, Sama C, Morselli Labate AM, et al. A population study on the prevalence of gallstone disease: the Sirmione study. Hepatology 1987;7:913-7.

3. Jorgensen T. Gallstones in a Danish population: fertility period, pregnancies, and exogenous female sex hormones. Gut 1988;29:433-9.

4. The epidemiology of gallstone disease in Rome, Italy. Part II. Factors associated with the disease. The Rome Group for the Epidemiology and Prevention of Cholelithiasis (GREPCO). Hepatology 1988;8:907-13.

5. Friedman GD, Kannel WB, Dawber TR. The epidemiology of gallbladder disease: observations in the Framingham Study. J Chronic Dis 1966;19:273-92.

6. Attili AF, Capocaccia R, Carulli N, et al. Factors associated with gallstone disease in the MICOL experience. Multicenter Italian Study on Epidemiology of Cholelithiasis. Hepatology 1997;26:809-18.

7. Valdivieso V, Covarrubias C, Siegel F, Cruz F. Pregnancy and cholelithiasis: pathogenesis and natural course of gallstones diagnosed in early puerperium. Hepatology 1993;17:1-4.

8. Glasinovic JC, Mege RM, Ferreiro O, et al. Cholelithiasis in a Chilean female population: prevalence and associated risk factors. Gastroenterology 1989;96:A601.

9. Maringhini A, Ciambra M, Baccelliere P, et al. Biliary sludge and gallstones in pregnancy: incidence, risk factors, and natural history. Ann Intern Med 1993;119:116-20.

10. Tsimoyiannis EC, Antoniou NC, Tsaboulas C, Papanikolaou N. Cholelithiasis during pregnancy and lactation. Prospective study. Eur J Surg 1994;160:627-31.

11. Swisher SG, Schmidt PJ, Hunt KK, et al. Biliary disease during pregnancy. Am J Surg 1994;168:576-81.

12. Davis A, Katz VL, Cox R. Gallbladder disease in pregnancy. J Reprod Med 1995;40:759-62.

13. Maringhini A, Marceno MP, Lanzarone F, et al. Sludge and stones in gallbladder after pregnancy. Prevalence and risk factors. J Hepatol 1987;5:218-23.
This phenomenon is usually attributed to high estrogen levels, which rise progressively during pregnancy. In monkeys, it has been shown (32) that the dose-dependent administration of estrogens reduces bile acid secretion, with a concomitant reduction in bile flow. Estrogens also act on key enzymes such as 3-hydroxy-3-methylglutaryl-coenzyme A reductase and $7 \alpha$-hydroxylase, usually increasing the former and reducing the latter. The results from studies of various animal species, however, are not uniform $(33,34)$.

The secretion of cholesterol-supersaturated bile should not be uncritically ascribed to estrogens only. When gallstones are induced, mainly by gallbladder stasis in experimental animals or humans, typical changes are also found in the chemical composition of bile. This has been demonstrated in patients treated by octreotide (27) and, to a lesser degree, by parenteral alimentation (35). There may thus be an interaction between the effects of estrogens and progesterones, with both contributing to lithogenic results.

\section{SUMMARY}

The lithogenic effects of pregnancy on the biliary tract are summarized in Table 6 . There is proof that pregnancy may induce the formation of biliary sludge and cholesterol gallstones. The mechanisms contributing to these complications are mostly the physiological effects of pregnancy on the biliary tract.

14. Strasberg SM. Cholelithiasis and acute cholecystitis. Baillieres Clin Gastroenterol 1997;11:643-61.

15. Glasgow RE, Visser BC, Harris HW, Patti MG, Kilpatrick SJ, Mulvihill SJ. Changing management of gallstone disease during pregnancy. Surg Endosc 1998;12:241-6.

16. Smoleniec JS, James DK. Gastro-intestinal crises during pregnancy. Dig Dis 1993;11:313-24.

17. Jamidar PA, Beck GJ, Hoffman BJ, et al. Endoscopic retrograde cholangiopancreatogaphy in pregnancy. Am J Gastroenterol 1995;90:1263-7.

18. Lee SP, Maher K, Nicholls JF. Origin and fate of biliary sludge. Gastroenterology 1988;94:170-6.

19. Messing B, Bories C, Kunstlinger F, Bemier JJ. Does total parenteral nutrition induce gallbladder sludge formation and lithiasis? Gastroenterology 1983;84:1012-9.

20. Angelico M, De Santis A, Capocaccia L. Biliary sludge: a critical update. J Clin Gastroenterol 1990;12:656-62.

21. Carey MC, Cahalane MJ. Whither biliary sludge? Gastroenterology 1988;95:508-23.

22. Everson GT. Gallbladder function in Gallstone disease. Gastroenterol Clin North Am 1991;20:85-110.

23. Everson GT. Gastrointestinal motility in pregnancy. Gastroenterol Clin North Am 1992;21:751-76.

24. Festi D, Frabboni R, Bazzoli F, et al. Gallbladder motility in cholesterol gallstone disease. Effect of ursodeoxycholic acid administration and gallstone dissolution. Gastroenterology 1990;99:1779-85.

25. Berr F, Mayer M, Sackmann MF, Sauerbruch T, Holl G, Paumgartner G. Pathogenic factors in early recurrence of cholesterol gallstones. Gastroenterology 1994;106:215-24.

26. Roslyn JJ, Pitt HA, Mann LL, Ament ME, DenBesten L. Gallbladder disease in patients on long-term parenteral nutrition. Gastroenterology 1983;84:148-54.

27. Hussaini SH, Pereira SP, Veysey MJ, et al. Roles of gallbladder emptying and intestinal transit in the pathogenesis of octreotide induced gallbladder stones. Gut 1996;38:775-83.

28. van Berge Henegouwen MI, van Gulik TM, Akkerinans LM, Jansen JB, Gouma DJ. The effect of octreotide on gastric emptying at 
a dosage used to prevent complications after pancreatic surgery: a randomized, placebo controlled study in volunteers. Gut 1997;41:758-62.

29. Dowling RH, Veysey MJ, Pereira SP, et al. Role of intestinal transit in the pathogenesis of gallbladder stones. Can J Gastroenterol 1997;11:57-64.

30. Heaton KW, Emmett PM, Symes CL, Braddon FE. An explanation for gallstones in normal-weight women: slow intestinal transit. Lancet 1993;341:8-10.

31. Kern F Jr, Everson GT, DeMark B, et el. Biliary lipids, bile acids, and gallbladder function in the human female. Effects of pregnancy and the ovulatory cycle. J Clin Invest 1981;68:1229-42.

32. Lynn J, Williams L, O'Brien J, Wittenberg J, Egdahl RH. Effects of estrogen upon bile: implications with respect to gallstone formation. Ann Surg 1973:178:514-24.

33. Coyne MJ, Bonorris GG, Chung A, Winchester R, Schoenfield LJ. Estrogen enhances dietary cholesterol induction of saturated bile in the hamster. Gastroenterology 1978;75:76-9.

34. Del Pozo R, Nervi F, Covarrubias C, Ronco B. Reversal of progesterone-induced biliary cholesterol output by dietary cholesterol and ethynylestradiol. Biochim Biophys Acta 1983;753:164-72.

35. Rubin M, Halpem Z, Charach G, et al. Effect of lipid infusion on bile composition and lithogenicity in patients without cholesterol gall stones. Gut 1992;33:1400-3. 


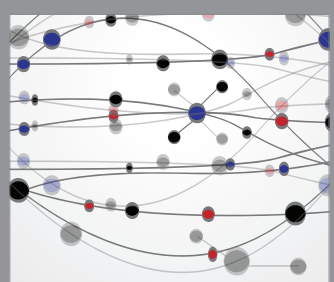

The Scientific World Journal
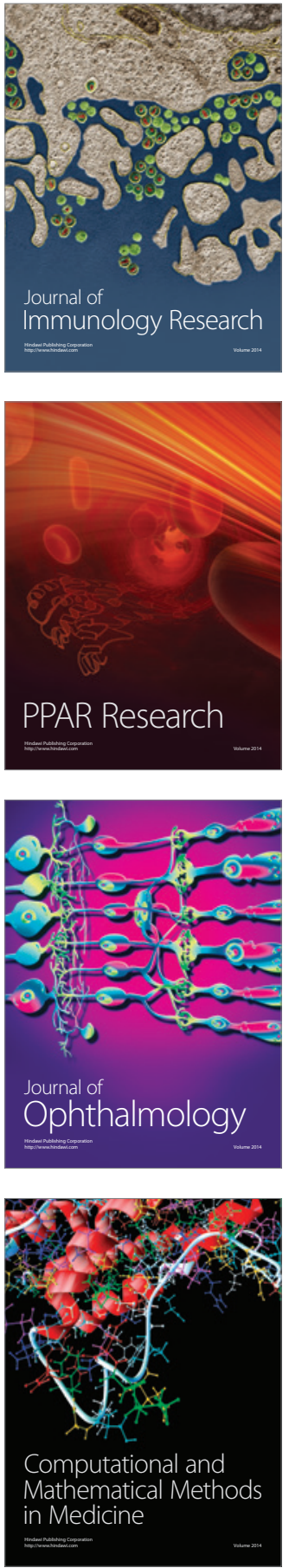

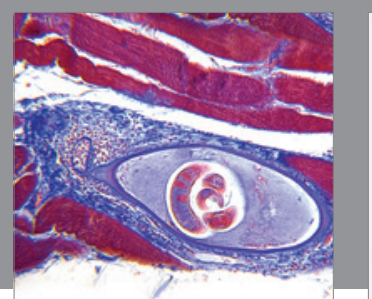

Gastroenterology Research and Practice

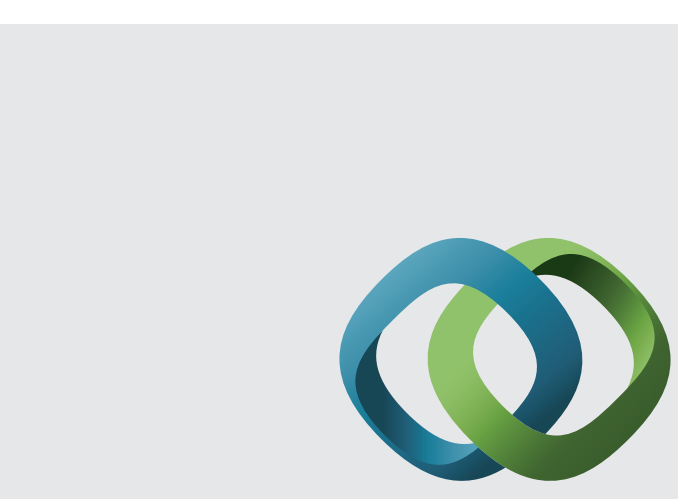

\section{Hindawi}

Submit your manuscripts at

http://www.hindawi.com
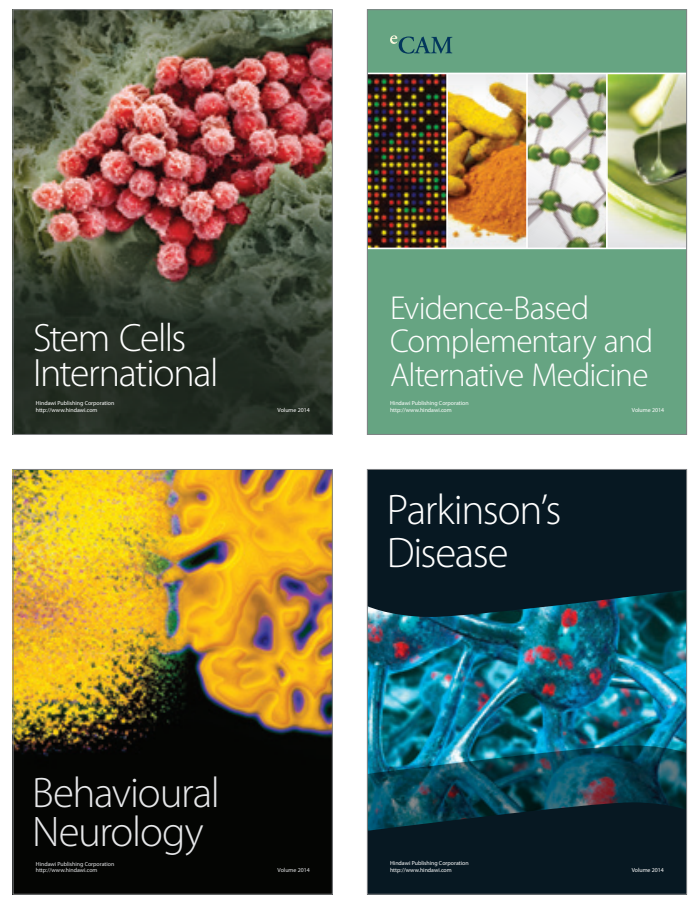
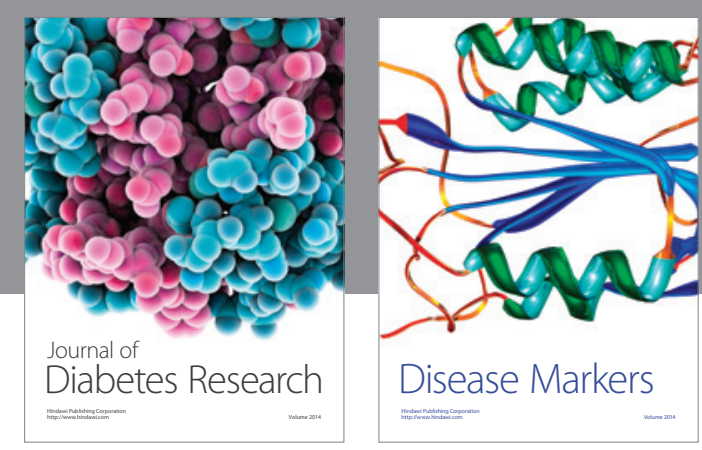

Disease Markers
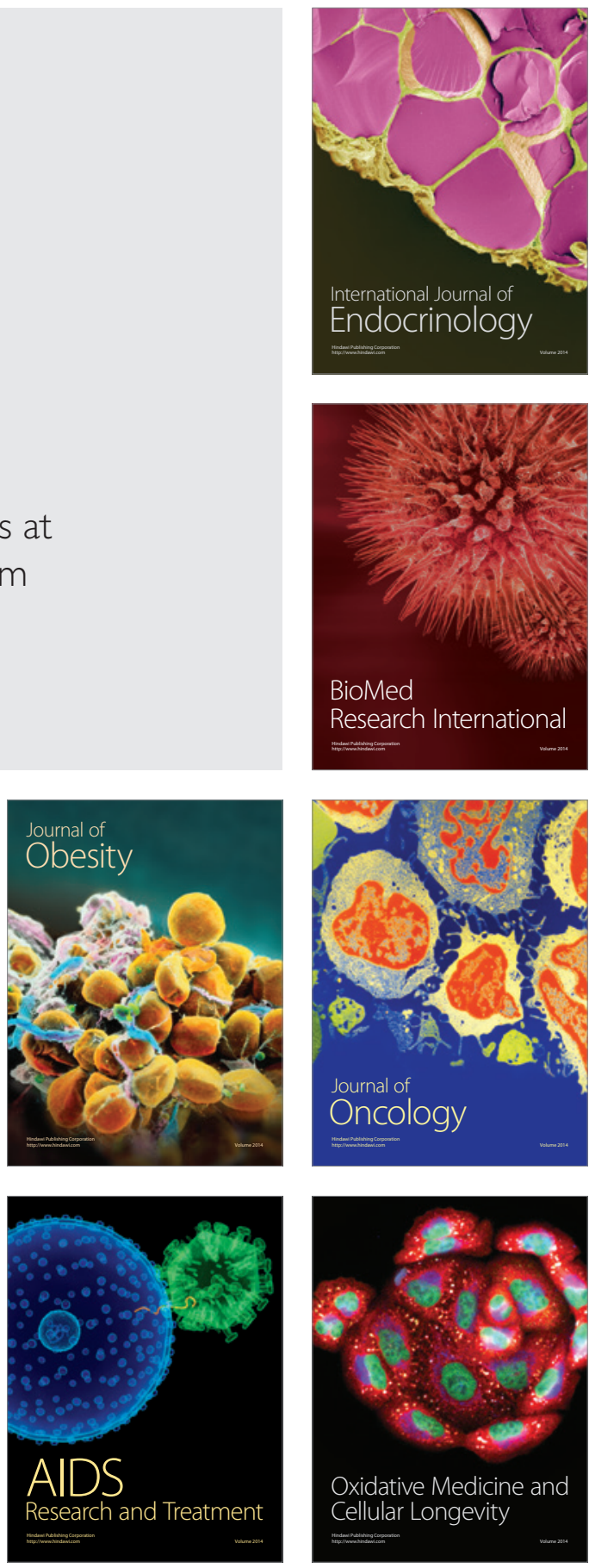